\title{
Hot Deformation Behavior of a Spray-Deposited Al-8.31Zn-2.07Mg-2.46Cu-0.12Zr Alloy
}

\author{
Xiaofei Sheng ${ }^{1,2}$, Qian Lei ${ }^{1,3, *}$, Zhu Xiao ${ }^{1}$ and Mingpu Wang ${ }^{1}$ \\ 1 School of Materials Science and Engineering, Central South University, Changsha 410083, China; \\ auden1@126.com (X.S.); xiaozhumse@163.com (Z.X.); wangmp@csu.edu.cn (M.W.) \\ 2 School of Materials Science and Engineering, Hubei University of Automotive Technology, \\ Shiyan 442002, China \\ 3 Department of Materials Science and Engineering, College of Engineering, University of Michigan, \\ Ann Arbor, MI 48109, USA \\ * Correspondence: qianlei@umich.edu; Tel.: +1-734-763-5282
}

Received: 20 June 2017; Accepted: 1 August 2017; Published: 4 August 2017

\begin{abstract}
Metallic materials have a significant number of applications, among which Al alloys have drawn people's attention due to their low density and high strength. High-strength Al-based alloys, such as 7XXX Al alloys, contain many alloying elements and with high concentration, whose microstructures present casting voids, segregation, dendrites, etc. In this work, a spray deposition method was employed to fabricate an Al-8.31Zn-2.07Mg-2.46Cu- $0.12 \mathrm{Zr}$ (wt \%) alloy with fine structure. The hot deformation behavior of the studied alloy was investigated using a Gleeble 1500 thermal simulator and electron microscopes. The microstructure evolution, variation in the properties, and precipitation behavior were systematically investigated to explore a short process producing an alloy with high property values. The results revealed that the $\mathrm{MgZn}_{2}$ particles were detected from inside the grain and grain boundary, while some $\mathrm{Al}_{3} \mathrm{Zr}$ particles were inside the grain. An Arrhenius equation was employed to describe the relationship between the flow stress and the strain rate, and the established constitutive equation was that: $\dot{\varepsilon}=[\sinh (0.017 \sigma)]^{4.049} \exp [19.14-(129.9 / R T)]$. An appropriate hot extrusion temperature was determined to be $460{ }^{\circ} \mathrm{C}$. Hot deformation $\left(460^{\circ} \mathrm{C}\right.$ by $60 \%)+$ age treatment $\left(120^{\circ} \mathrm{C}\right)$ was optimized to shorten the processing method for the as-spray-deposited alloy, after which considerable properties were approached. The high strength was mainly attributed to the grain boundary strengthening and the precipitation strengthening from the nanoscale $\mathrm{MgZn}_{2}$ and $\mathrm{Al}_{3} \mathrm{Zr}$ precipitates.
\end{abstract}

Keywords: alloy; 7XXX Al alloy; spray deposited; hot deformation behavior; precipitation

\section{Introduction}

Aluminum alloys of the 7XXX series (Al-Zn-Mg-Cu) have a large number of applications in automobile and aviation industries because of their considerable combination of properties, e.g., high strength, low density, outstanding workability, etc. [1-4]. Their excellent performance attracts much interest from the manufacturing industry $[5,6]$. High strength makes these products strong, and good ductility allows them to be formed and deformed easily. Meanwhile, high fatigue strength and lifetime are related to the strength and ductility. Strength and ductility are equally important in the damage tolerance and durability $[7,8]$. Precipitation hardening plays an important role in strengthening the 7XXX aluminum alloys [9]. Increasing the additions of $\mathrm{Zn}$ and $\mathrm{Mg}$ will enhance the volume fraction of precipitates and improve the mechanical properties [10]. However, a large amount of $\mathrm{Zn}$ and $\mathrm{Mg}$ results in coarse grains and segregation in ingots and results in poor ductility and low fracture strength [11]. Moreover, the 7XXX alloys with high Zn and Mg content were easy to failure in service. An important and effective way to approach the superior properties is by refining the structure, within 
which thermal-mechanical heat treatment and severe plastic deformation have been developed in the past decade. Severe plastic deformation techniques, such as equal-channel accumulative roll bonding [12], angular pressing [13], high-pressure torsion, and friction stir processing [14], are effective approaches to refine the microstructure. However, the above techniques yield small sizes and quantities in the laboratory, but are not suitable for industrialized production [15]. Fortunately, spray deposition technology has been used to manufacture high-performance 7XXX series aluminum alloys in the past [16]. Spray forming combines the advantages of rapid solidification, high solute content, and homogeneous microstructure containing fine grains, avoiding the macro segregation. Thus, it is thought that the spray deposition technique could be used to enhance the mechanical properties of aluminum alloys. The additions of $\mathrm{Mg}$ and $\mathrm{Zn}$ enhanced the mechanical properties because of the $\eta^{\prime}-\mathrm{MgZn}_{2}$ precipitates after the aging treatment $[17,18]$. The addition of other alloying elements were also effective to enhance the properties. The additions and $\mathrm{Zr}$ and $\mathrm{Sc}$ could be precipitated as $\mathrm{Al}_{3}(\mathrm{Sc}, \mathrm{Zr})$ precipitates during aging treatment, and these precipitates are functionally important in pinning the dislocation and preventing grain boundary migration. As a result, the yield strength was enhanced $[19,20]$.

Therefore, an Al-8.31Zn-2.07Mg-2.46Cu-0.12Zr alloy (wt \%) was designed, fabricated by the spray deposition solidification method, and investigated to develop a novel high-strength high-ductility aluminum alloy. Previous research on spray forming Al-Zn-Mg-Cu alloy only focused on the microstructure and properties of the spray-deposited ingots [21,22], and the thermal-mechanical treatment that was an important and efficient method to improve the properties. In previous decades, most researchers have focused on the melting, casting, homogenization-processed solid solution treatment, aging treatment, and so forth. Precipitation behavior, the crystal orientation relationship between matrix and precipitates, homogenization behavior, recovery, crystallization behavior, and cold working hardening have been reported in the past decades. However, hot deformation and shortened processing have not been reported yet.

In this work, an $\mathrm{Al}-8.31 \mathrm{Zn}-2.07 \mathrm{Mg}-2.46 \mathrm{Cu}-0.12 \mathrm{Zr}$ alloy was prepared by the spray deposition method. Subsequently, the hot deformation behavior of the above alloy ingot was investigated systematically. The constitutive equation, hot working map, microstructure evolution, precipitation of the compressed samples, and strength mechanism was explored in this work. For the industry baseline, a shorter processing was developed on the basis of the hot compressed result.

\section{Materials and Methods}

The composition of the studied alloy was Al-8.31Zn-2.07Mg-2.46Cu-0.12Zr (wt \%). The ingots were prepared using an SFZD-5000 type environmental chamber at Haoran Co., Ltd., Jiangsu, China [23]. Then the spray-deposited ingot was cut into small cylindrical samples with a dimension of $10 \mathrm{~mm}$ in diameter and $15 \mathrm{~mm}$ in height. Hot deformation experiments were carried out on the Gleeble-1500 thermal simulator (Dynamic Systems Inc., Poestenkill, NY, USA); the strain rates were $0.001 \mathrm{~s}^{-1}$, $0.01 \mathrm{~s}^{-1}, 0.1 \mathrm{~s}^{-1}$, and $1 \mathrm{~s}^{-1}$, and the deformation temperatures were $340{ }^{\circ} \mathrm{C}, 380^{\circ} \mathrm{C}, 420^{\circ} \mathrm{C}$, and $460{ }^{\circ} \mathrm{C}$, respectively. The total deformation for each sample was $60 \%$. Hardness values were measured with an HV-5 hardness tester (Laizhou Huayin Testing Instrument Co., Ltd., Laizhou, China), with a load of $2 \mathrm{~kg}$ and a load time of $15 \mathrm{~s}$, each average hardness was taken from at least seven measurements. The X-ray diffraction analyses on polished discs samples were performed using a D8 Discover X-ray diffractometer (Bruker AXS Inc., Karlsruhe, Germany), with a scanning step of $8^{\circ} / \mathrm{min}$, a $\mathrm{Cu}-\mathrm{K} \alpha$ radiation graphite monochromator filtering, a tube voltage of $40 \mathrm{kV}$, a tube current of $250 \mathrm{~mA}$. The X-ray diffraction (XRD) result was analyzed with an MDI Jade software (5.0, MDI, Livermore, CA, USA). Phase identification was conducted on an FEI Quanta 650 scanning electron microscopy (SEM) (FEI Company, Hillsboro, OR, USA) with an electron back-scattered diffraction (EBSD) detector. The differential scanning calorimetry (DSC) analysis test was conducted on SDT-Q600 differential thermal equipment (Ta Instruments, New Castle, DE, USA). The sample was heated in an argon gas environment, the heating rate is $10^{\circ} \mathrm{C} / \mathrm{min}$, the heating temperature region is $25-680^{\circ} \mathrm{C}$, the reference sample is $\mathrm{Al}_{2} \mathrm{O}_{3}$. Optical microscopy was performed on a Leica DM microscope (Leica Microsystems, Wetzlar, Germany), and samples were 
etched by Keller's reagent after grinding and polishing. The transmission electron microscopy (TEM) samples were prepared by dual-jet electropolishing technique with a solution containing $30 \%$ nitric acid and $70 \%$ methanol at $-30^{\circ} \mathrm{C}$. Transmission electron microscopy (TEM) observations were carried out on a TECNAI G2 F20 transmission electron microscope (FEI Company, Hillsboro, OR, USA) with an operation voltage of $200 \mathrm{kV}$.

\section{Results}

\subsection{Initial Microstructure of As-Spray-Deposited Samples}

Figure 1 shows back-scattered electros images (BSE) and XRD of the as-spray-deposited $\mathrm{Al}-\mathrm{Zn}-\mathrm{Mg}-\mathrm{Cu}-\mathrm{Zr}$ alloy. The average grain size was about $50 \pm 10 \mu \mathrm{m}$ after measurements (more than 60 grains were counted and measured from BSE SEM images). The XRD result and index revealed that some $\mathrm{MgZn}_{2}$ intermetallic compounds were formed in the as-spray-deposited samples (Figure 1c). Figure 2 shows the EBSD phase identify results of the as-spray-deposited alloy. $\mathrm{MgZn}_{2}$ and $\mathrm{Al}_{3} \mathrm{Zr}$ phases were detected from the EBSD results. The $\mathrm{MgZn}_{2}$ particles were distributed in the grain and on the grain boundary, while the $\mathrm{Al}_{3} \mathrm{Zr}$ particles distributed inside the grain at the nanoscale. The white contrast particles in Figures $1 \mathrm{~b}$ and $2 \mathrm{a}$ were determined to be $\mathrm{MgZn_{2 }}$. For the as-spray-deposited sample, there are no dendrites and segregation due to rapid solidification, as shown in Figures 1 and 2.

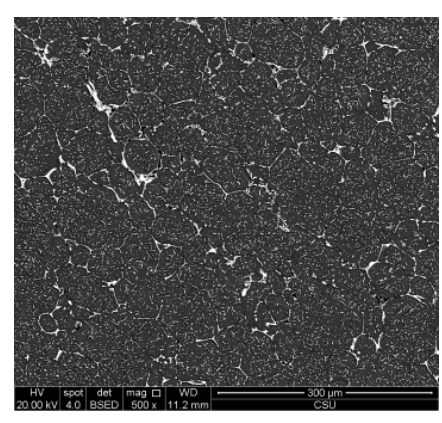

(a)

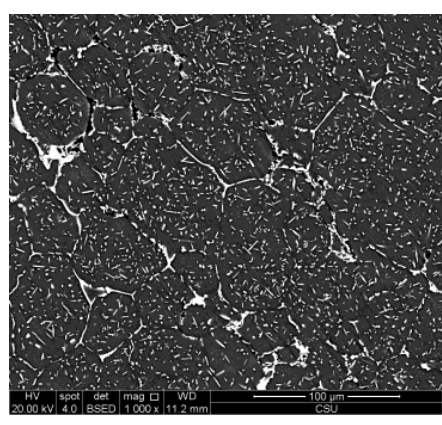

(b)

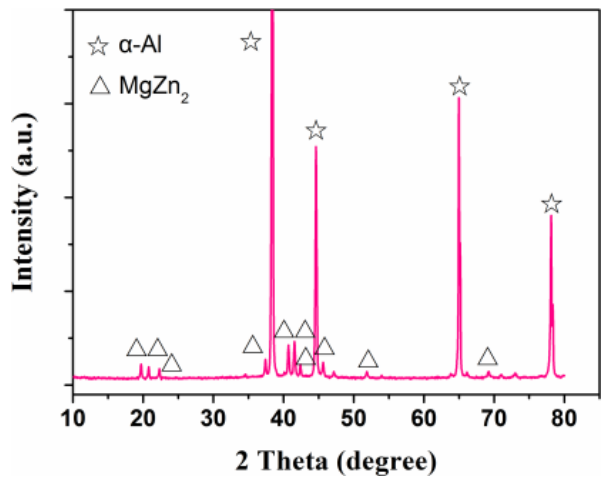

(c)

Figure 1. Back-scattered electrons images (a,b) and XRD (X-ray diffraction) pattern (c) of as-spray-deposited $\mathrm{Al}-8.31 \mathrm{Zn}-2.07 \mathrm{Mg}-2.46 \mathrm{Cu}-0.12 \mathrm{Zr}$ alloy.

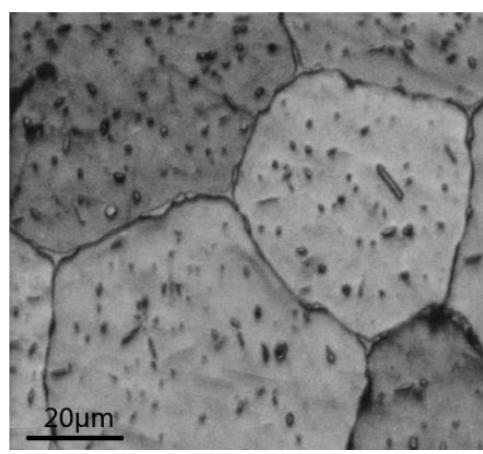

(a)

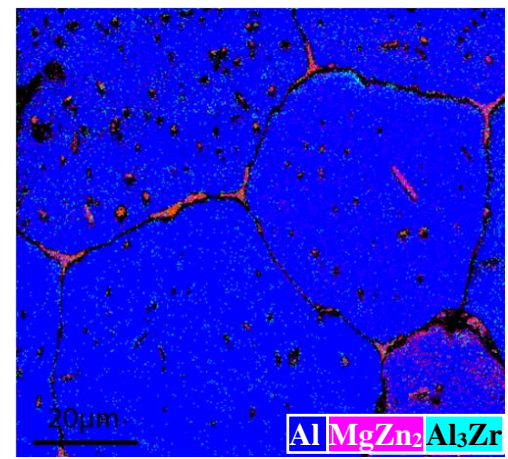

(b)

Figure 2. The SEM image and EBSD phase map of as-spray-deposited Al-8.31Zn-2.07Mg-2.46Cu-0.12Zr alloy: (a) secondary electron image; (b) EBSD phase maps showing the detected phases and their distribution. 


\subsection{Compressive Stress-Strain Curves}

Hot-deformation is an effective way to refine the structure, to eliminate the defects, and to shape the structural parts. Figure 3 shows the true stress-true strain of the as-spray-deposited samples after hot-compressive deformation at $340-460{ }^{\circ} \mathrm{C}$ with strain rates of $0.001-1 \mathrm{~s}^{-1}$. As the samples were hot compressed at $340{ }^{\circ} \mathrm{C}$ and $380{ }^{\circ} \mathrm{C}$, the true-stress was rapidly increased with the true-strain at the early deformation process, and then slowly increased with the strain after a true strain of around $5 \%$ due to the balance between hardening and recovery softening. As the samples were hot compressed at $420{ }^{\circ} \mathrm{C}$ and $460^{\circ} \mathrm{C}$, the true-stress rapidly increased to a mountain peak and then decreased, followed by slowly increasing with the strain when the strain rate was less than $0.1 \mathrm{~s}^{-1}$. The decline in true-stress contributed to the softening from the grains' subdivision and the coarsening of initial grains. The true-stress increased with the strain rate when the sample was hot-compressed at a certain temperature, while the true-stress decreased with the deformation temperature.

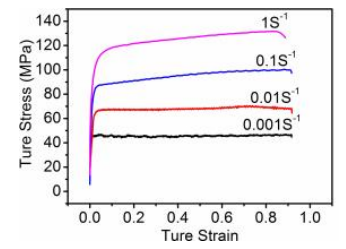

(a)

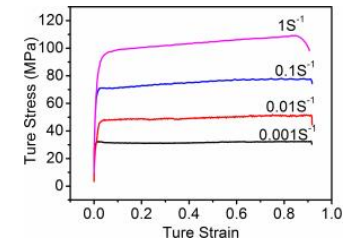

(b)

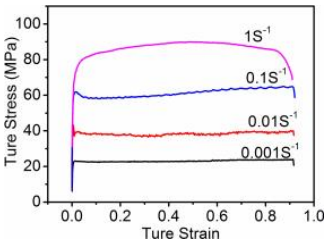

(c)

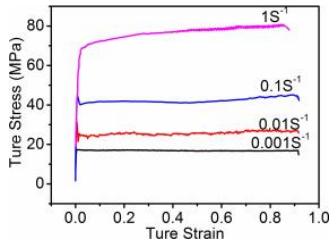

(d)

Figure 3. True stress-true strain curves of the specimens hot compressed at temperatures of $340{ }^{\circ} \mathrm{C}(\mathbf{a})$; $380^{\circ} \mathrm{C}(\mathbf{b}) ; 420^{\circ} \mathrm{C}(\mathbf{c})$; and $460{ }^{\circ} \mathrm{C}$; and (d) with different strain rates $\left(0.001-1 \mathrm{~s}^{-1}\right)$.

\subsection{Microstructure Evolution}

EBSD orientation mapping is an advanced technology to present the microstructure of the deformed samples, especially for aluminum alloys. Figure 4 shows the EBSD orientation maps of the samples after hot-compression at different temperatures with strain rates of $1 \mathrm{~s}^{-1}$ and $0.001 \mathrm{~s}^{-1}$. The red lines in Figure 4 presented large angle grain boundaries (larger than 15 degrees), and green lines showed small angle grain boundaries (less than 15 degrees). The fraction of small angle grain boundaries decreased with the deformation temperature when the strain rate was $0.001 \mathrm{~s}^{-1}$, while remaining constant at a strain rate of $1 \mathrm{~s}^{-1}$, even if the deformation temperature increased. The grain size was increased when the deformation temperature was increased from $340{ }^{\circ} \mathrm{C}$ to $460{ }^{\circ} \mathrm{C}$ for the strain rate of $0.001 \mathrm{~s}^{-1}$. Figure 5 shows the area fraction of the grain size in the compressed samples, on the basis of the EBSD mapping results from Figure 4. The grain size was 40-65 $\mu \mathrm{m}$ when the strain rate was $0.001 \mathrm{~s}^{-1}$, while it was $0-30 \mu \mathrm{m}$ when the strain rate was $1 \mathrm{~s}^{-1}$. Figure 6 shows SEM images of samples hot-compressed at $340-460^{\circ} \mathrm{C}$ with different deformation rates of $1 \mathrm{~s}^{-1}$ and $0.001 \mathrm{~s}^{-1}$. As compared with the as-spray-deposited microstructure (Figure 1b), the fraction of $\mathrm{MgZn}_{2}$ phase decreased when the sample was hot compressed at elevated temperatures. The fraction of the $\mathrm{MgZn} 2$ phase decreased with the hot deformation temperature. The fraction of the $\mathrm{MgZn} 2$ in the samples compressed at a certain temperature decreased with the decrease of the strain rate (from $1 \mathrm{~s}^{-1}$ to $0.001 \mathrm{~s}^{-1}$ ).

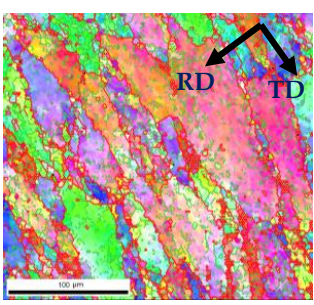

(a)

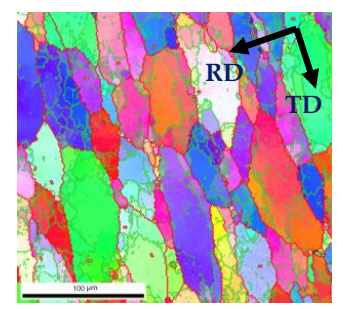

(b)

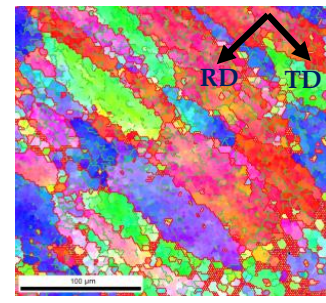

(c)

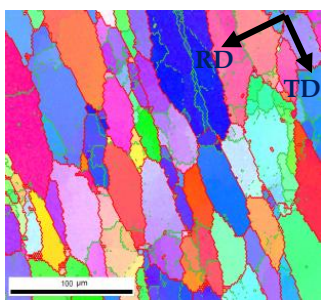

(d)

Figure 4. Cont. 


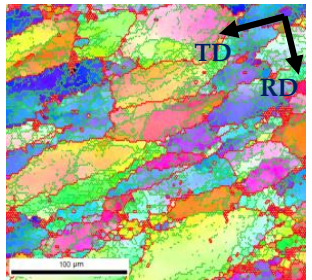

(e)

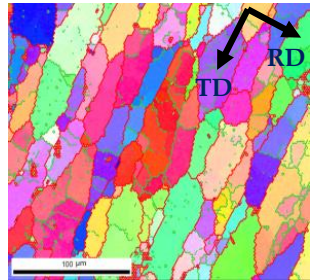

(f)

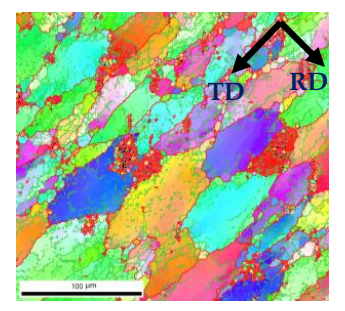

(g)

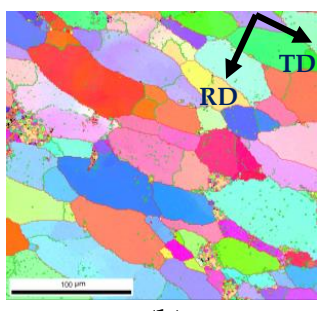

(h)

Figure 4. Typical EBSD orientation maps: (a) $340{ }^{\circ} \mathrm{C}, 1 \mathrm{~s}^{-1}$; (b) $340{ }^{\circ} \mathrm{C}, 0.001 \mathrm{~s}^{-1}$; (c) $380{ }^{\circ} \mathrm{C}, 1 \mathrm{~s}^{-1}$; (d) $380{ }^{\circ} \mathrm{C}, 0.001 \mathrm{~s}^{-1}$; (e) $420{ }^{\circ} \mathrm{C}, 1 \mathrm{~s}^{-1}$; (f) $420{ }^{\circ} \mathrm{C}, 0.001 \mathrm{~s}^{-1}$; (g) $460{ }^{\circ} \mathrm{C}, 1 \mathrm{~s}^{-1}$; and (h) $460{ }^{\circ} \mathrm{C}, 0.001 \mathrm{~s}^{-1}$.

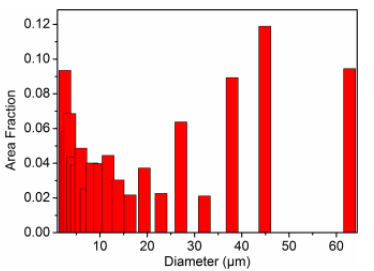

(a)

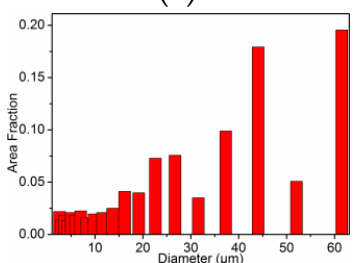

(e)

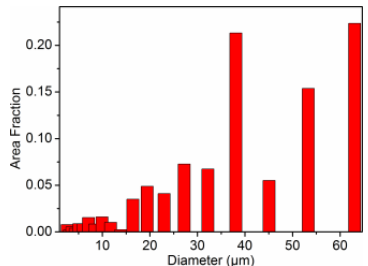

(b)

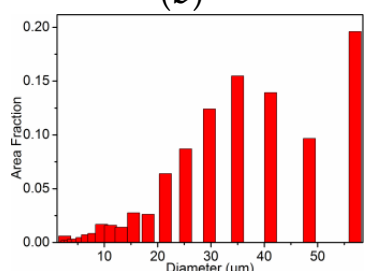

(f)

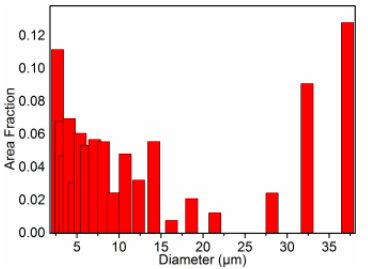

(c)

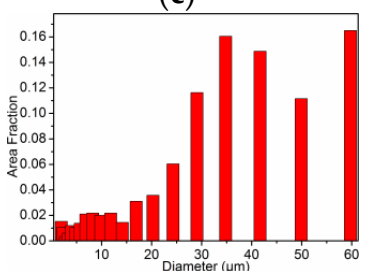

(g)

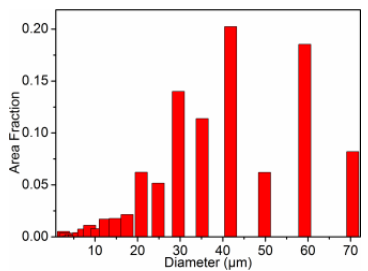

(d)

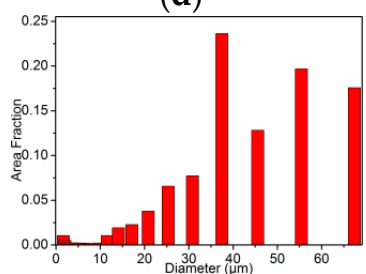

(h)

Figure 5. Variations of gain size in the samples after hot-compressing with different conditions: (a) $340{ }^{\circ} \mathrm{C}, 1 \mathrm{~s}^{-1}$; (b) $340{ }^{\circ} \mathrm{C}, 0.001 \mathrm{~s}^{-1}$; (c) $380{ }^{\circ} \mathrm{C}, 1 \mathrm{~s}^{-1}$; (d) $380{ }^{\circ} \mathrm{C}, 0.001 \mathrm{~s}^{-1}$; (e) $420{ }^{\circ} \mathrm{C}, 1 \mathrm{~s}^{-1}$; (f) $420{ }^{\circ} \mathrm{C}, 0.001 \mathrm{~s}^{-1}$; (g) $460{ }^{\circ} \mathrm{C}, 1 \mathrm{~s}^{-1}$; and (h) $460{ }^{\circ} \mathrm{C}, 0.001 \mathrm{~s}^{-1}$.

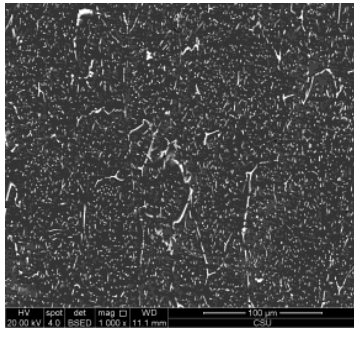

(a)

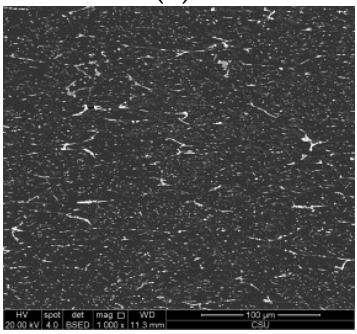

(e)

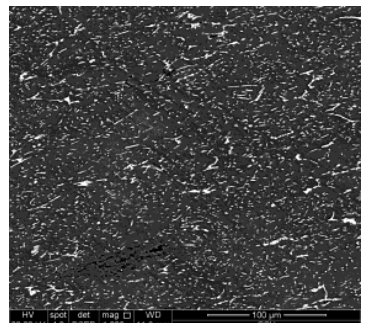

(b)

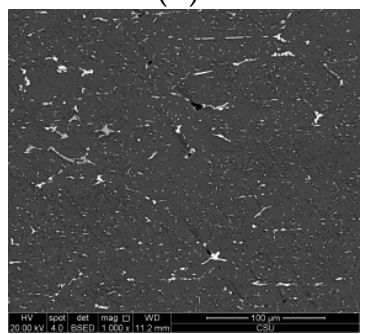

(f)

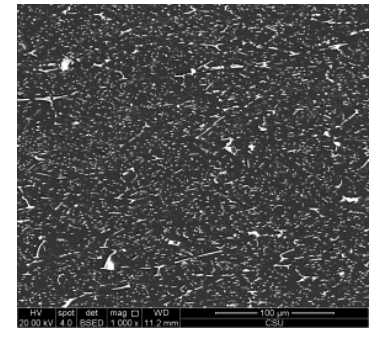

(c)

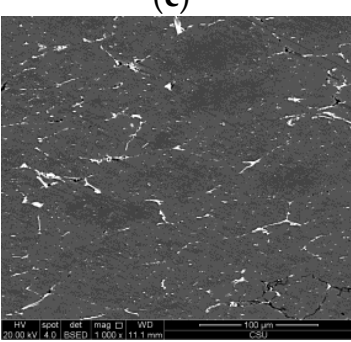

(g)

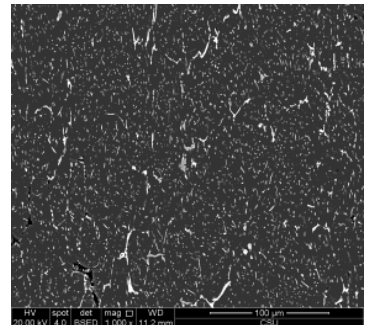

(d)

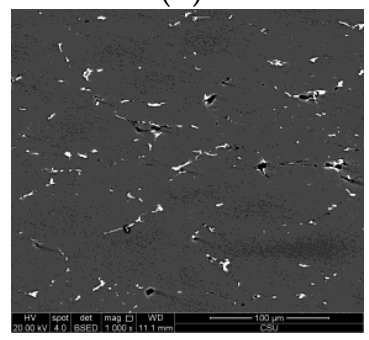

(h)

Figure 6. Back-scattered electron SEM images: (a) $340{ }^{\circ} \mathrm{C}, 1 \mathrm{~s} \mathrm{~s}^{-1}$; (b) $340{ }^{\circ} \mathrm{C}, 0.001 \mathrm{~s}^{-1}$; (c) $380{ }^{\circ} \mathrm{C}, 1 \mathrm{~s}^{-1}$; (d) $380^{\circ} \mathrm{C}, 0.001 \mathrm{~s}^{-1}$; (e) $420^{\circ} \mathrm{C}, 1 \mathrm{~s}^{-1}$; (f) $420^{\circ} \mathrm{C}, 0.001 \mathrm{~s}^{-1}$; (g) $460{ }^{\circ} \mathrm{C}, 1 \mathrm{~s}^{-1}$; and (h) $460{ }^{\circ} \mathrm{C}, 0.001 \mathrm{~s}^{-1}$. 


\subsection{Hardness of the Compressive Samples after Age Treatments}

Figure 7 gives the hardness variations of the hot compressed samples aged at $120{ }^{\circ} \mathrm{C}$ for different durations. For the samples after being hot-compressed at strain rates of $1 \mathrm{~s}^{-1}$ and $0.001 \mathrm{~s}^{-1}$, the curves present the same trend. The initial hardness of compressed samples increased with the hot deformation temperature. The hardness of the hot-compressed samples increased with the aging time, and almost kept constant as they were aging at certain temperatures for $15 \mathrm{~h}$.

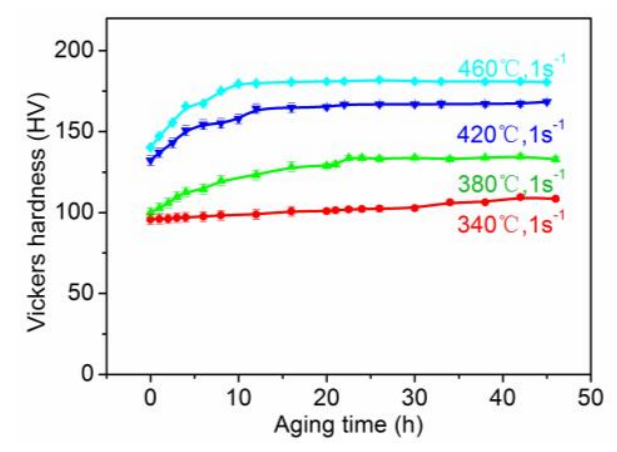

(a)

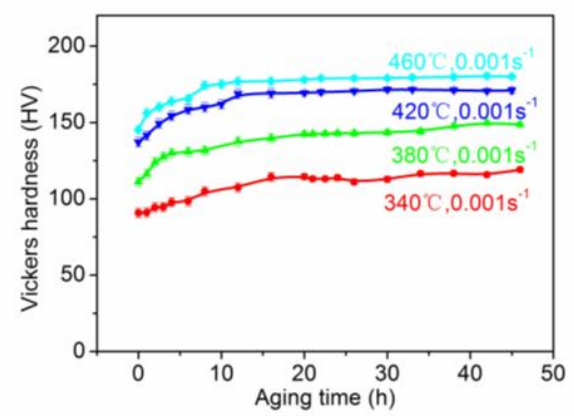

(b)

Figure 7. Hardness variation of the hot-compressed samples with an aging time at $120^{\circ} \mathrm{C}$. The samples were compressed with strain rates of: (a) $1 \mathrm{~s}^{-1}$; and (b) $0.001 \mathrm{~s}^{-1}$.

\section{Discussion}

\subsection{Constitutive Equation}

The constitutive relationships were used to describe the hot deformation behavior. Some models are employed to reveal the hot deformation behavior, in which one of the most extended versions of the hot working constitutive equation is as follows [24]:

$$
\dot{\varepsilon}=A F(\sigma) \exp [-Q /(R T)],
$$

where $\dot{\varepsilon}$ is the strain rate; $A$ is a material constant which is independent of temperature; $\sigma$ is peak true stress; $Q$ is the activation energy; $R$ is the gas constant (8.31); and $T$ is the absolute temperature (K).

At low stress lever $(\alpha \sigma<0.8)$ :

$$
F(\sigma)=\exp (\beta \sigma)
$$

At high stress lever $(\alpha \sigma>1.2)$ :

$$
F(\sigma)=\sigma^{n},
$$

$\beta$ and $n$ are the material constants, $\alpha=\beta / n$. Substituting Equations (2) and (3) into Equation (1):

$$
\begin{gathered}
\dot{\varepsilon}=A_{1} \exp (-Q / R T) \exp (\beta \sigma), \\
\dot{\varepsilon}=A_{2} \exp (-Q / R T) \sigma^{n},
\end{gathered}
$$

where parameters $B_{1}$ and $B_{2}$ are set to $B_{1}=A_{1} \exp (Q / R T)$ and $B_{2}=A_{2} \exp (Q / R T)$; when the temperature is fixed, $B_{1}$ and $B_{2}$ are temperature constants. Taking the logarithm of both sides of Equations (4) and (5), respectively, gives:

$$
\begin{gathered}
\ln \dot{\varepsilon}=\ln B_{1}+\beta \sigma, \\
\ln \dot{\varepsilon}=\ln B_{2}+n \ln \sigma,
\end{gathered}
$$


The values of $n$ and $\beta$ are from the slopes of the lines in $\ln \dot{\varepsilon}$ and $\sigma, \ln \dot{\varepsilon}$ and $\ln \sigma$, and plots, respectively. Figure 8 plotted them, the slope value of $\beta$ is 0.09491 , and the slope value $n$ is 5.512, $\alpha=\beta / n=0.01722$.

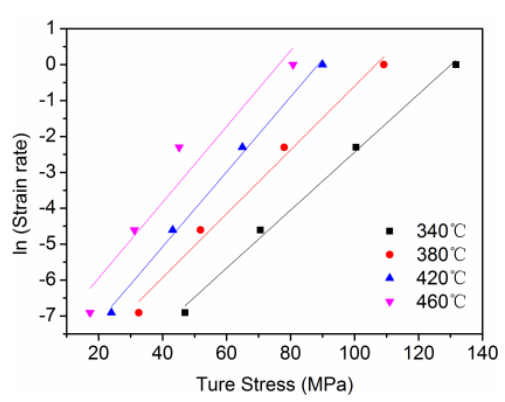

(a)

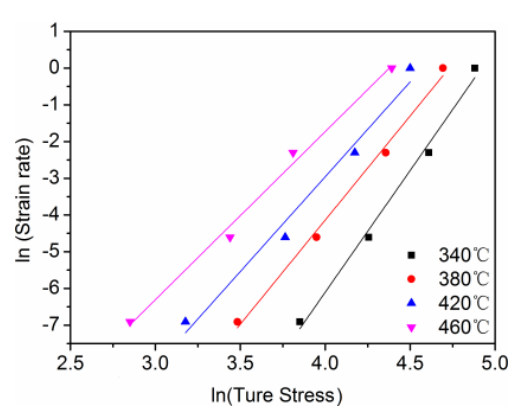

(b)

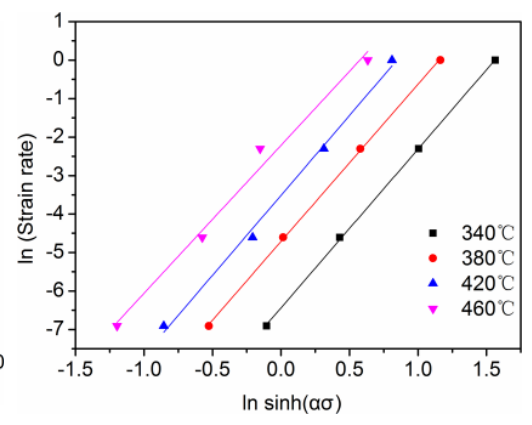

(c)

Figure 8. (a) $\ln \dot{\varepsilon}-\sigma ;$ (b) $\ln \dot{\varepsilon}-\ln \sigma ;(\mathbf{c}) \ln \dot{\varepsilon}-\ln [\sinh (\alpha \sigma)]$.

From Figure 8, it can be seen that the logarithm of the true stress and the logarithm of the strain rate met a linear relationship. In addition, flow stress, $F(\sigma)$, could be described by Equation (8):

$$
F(\sigma)=[\sinh (\alpha \sigma)]^{x}
$$

Substituting Equation (8) into Equation (1):

$$
\dot{\varepsilon}=A[\sinh (\alpha \sigma)]^{x} \exp [-Q /(R T)]=[\sinh (\alpha \sigma)]^{x} \exp [\ln A-Q /(R T)] .
$$

Taking the logarithm of both sides of Equation (9):

$$
\ln \dot{\varepsilon}=\ln A+x \ln [\sinh (\alpha \sigma)]-Q /(R T) .
$$

The value of $x$ can be obtained from the slope of the lines in $\ln \dot{\varepsilon}$ and $\ln [\sinh (\alpha \sigma)]$, shown in Figure 7c, and $x=4.053$.

Taking the Zener-Hollomon parameter [25]:

$$
Z=A[\sinh (\alpha \sigma)]^{x}=\dot{\varepsilon} \exp (Q / R T) .
$$

Taking the logarithm of both sides of Equation (11):

$$
\ln [\sinh (\alpha \sigma)]=(1 / x) \cdot(\ln \dot{\varepsilon}-\ln A)+(Q / 1000 x R) \cdot(1000 / T) .
$$

$x=4.053 . \ln [\sinh (\alpha \sigma)]-1000 / T$ could be imitated. From Figure $9 a, P=Q / 1000 x R=3.856$, and $Q=1000 P x R=129.9 \mathrm{~kJ} / \mathrm{mol}$. The activation energy of a studied material derived from Equation (11) was used as an indicator of the degree of difficulty for the material in the hot deformation process. It provides a guideline to optimize the hot working process, and also furnishes additional information on the microstructure and flow stress evolution in successive deformation processes.

According to Equation (11):

$$
\mathrm{Z}=A[\sinh (\alpha \sigma)]^{x},
$$

Taking the logarithm of both sides of Equation (13):

$$
\ln Z=\ln A+x \ln [\sinh (\alpha \sigma)],
$$




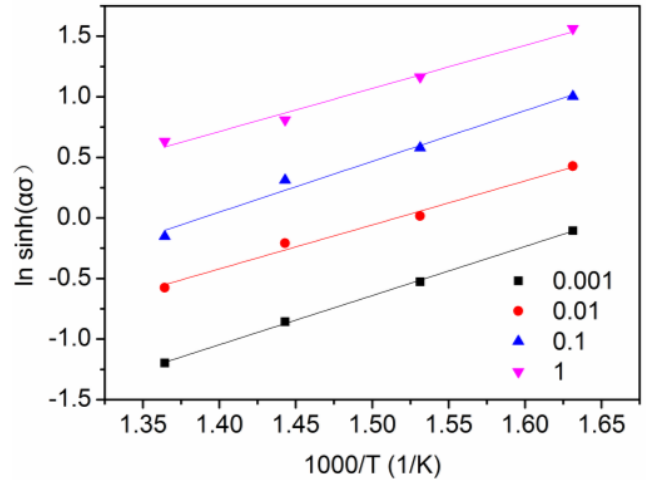

(a)

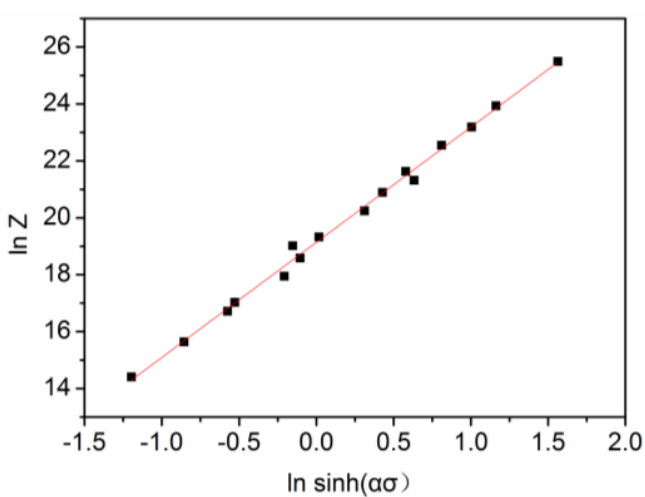

(b)

Figure 9. $\ln [\sinh (\alpha \sigma)]-1000 / T(\mathbf{a}) ; \ln Z-\ln [\sinh (\alpha \sigma)]$ (b).

Then, $Z=\dot{\varepsilon} \exp (Q / R T), R$ is the gas constant, and $Q$ is $129.9 \mathrm{~kJ} / \mathrm{mol}$. $\ln Z$ could be calculated from the slope of the fitting line in Figure $9 \mathrm{~b}$. $\ln A$ is 19.14, $x$ is 4.045, which is very close to $n$ (4.053). Here, taking the average value, $x=4.049$.

Substituting the values of $A, Q, x, \alpha$ into Equation (11), the flow stress constitutive equation for alloy can be expressed by the Arrhenius equation:

$$
\begin{gathered}
\dot{\varepsilon}=[\sinh \alpha \sigma]^{x} \exp [\ln A-(Q / R T)], \\
\dot{\varepsilon}=[\sinh (0.017 \sigma)]^{4.049} \exp [19.14-(129.9 / R T)] .
\end{gathered}
$$

\subsection{Hot Deformation Behavior}

In the first deformation, the true-stress increased rapidly (Figure 3). When the deformation temperature was constant, the stress peaks increased with the strain rate. When the deformation temperature is $340-460{ }^{\circ} \mathrm{C}$ and the strain rate is $0.001-0.1 \mathrm{~s}^{-1}$, the steady-state flow stress characteristic was the main phenomenon. At a certain temperature and a fixed strain rate, the performance of the dynamic recovery characteristics occurred when the true-strain exceeded a certain value (around $5 \%)$. With increasing the true-strain, the internal space of the material also increased the dislocation density, which was hardening the material, while dynamic recovery occurred; finally, the hardening and softening approached a balance. Thus, the curve for the true-stress and the true strain presents a horizontal line. The peak stress increases with both the decrease of the deformation temperature and the growth of the strain rate.

Figure 10a shows the differential scanning calorimetry (DSC) result of the as-spray-deposited specimen. There were two endothermic peaks in the DSC curve. Combined with XRD analysis result (Figure 1c), the endothermic peak at $474.2{ }^{\circ} \mathrm{C}$ is corresponding to the $\mathrm{MgZn}_{2}$ phase redissolution, the other one is corresponding to the melting point of the alloy matrix. Thus, the hot deformation temperature should be lower than $474.2{ }^{\circ} \mathrm{C}$. The temperature of the sample will increase when it was deformed at elevated temperature. An extrusion test was carried out at $470{ }^{\circ} \mathrm{C}$ for the as-spray-deposited alloy with an extrusion ratio of 6.25. The microstructure of the hot extruded sample is shown in Figure 10b, which shows a significant over-burning and widening of the grain boundaries. Thus, the hot deformation temperature should be less than $470{ }^{\circ} \mathrm{C}$. According to Figure $6 \mathrm{~d}$, $460^{\circ} \mathrm{C}$ was determined as the hot deformation temperature for the studied alloy. 


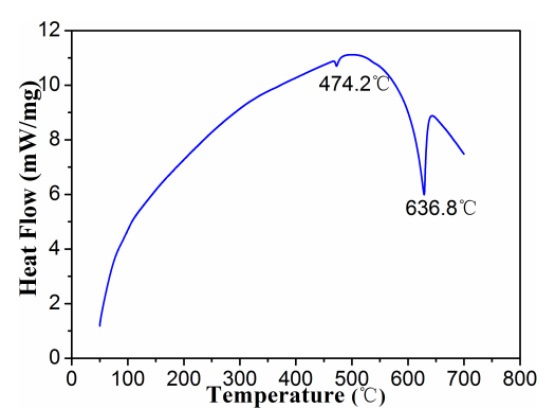

(a)

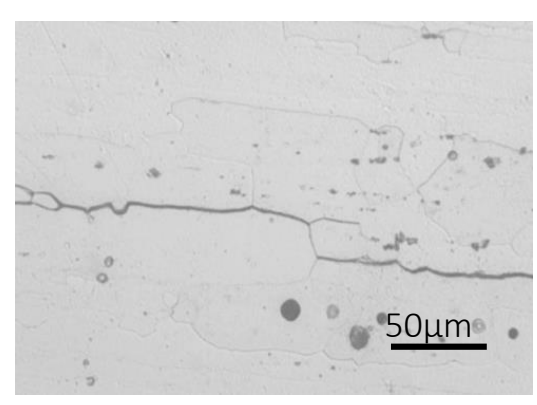

(b)

Figure 10. (a) The DSC results of the as-spray-deposited specimen; and (b) the microstructure of the sample after hot extrusion at $470{ }^{\circ} \mathrm{C}$ with an extrusion ratio of 6.2.

\subsection{Shortening the Production Process}

Homogenization was employed in the as-cast Al-Zn-Mg alloys (7XXX serious alloy) to eliminate the serious dendritic segregation before hot deformation in the previous investigations [26,27], for serious dendritic segregation. In this work, through spray deposition, the high composition $\mathrm{Al}-\mathrm{Zn}-\mathrm{Mg}$ alloys (7XXX serious alloy) were made without serious dendritic segregation. Moreover, the result of the test of hot deformation behavior means that here homogenization is not required for the spray-deposited Al-8.31Zn-2.07Mg-2.46Cu-0.12Zr alloy. For the Al-Zn-Mg-Cu-Zr system alloy, a very complex thermal-mechanical treatment path has been set up in a previous work (path I) [28]. On the basis of the above investigation, a simpler production processing method may be set up for the studied alloy; here, three other paths (paths I, II, III) referred to the previous work [28-30]. The four paths were listed as following: (I) as-deposited + homogenization treatment $\left(450{ }^{\circ} \mathrm{C} / 24 \mathrm{~h}+460{ }^{\circ} \mathrm{C} / 2 \mathrm{~h}\right)+$ hot deformation $\left(420^{\circ} \mathrm{C}\right.$ by 6.25$)+$ solid solution treatment $\left(470{ }^{\circ} \mathrm{C} / 1 \mathrm{~h}\right)+$ age treatment $\left(120^{\circ} \mathrm{C}\right)$ [28]; (II) as-spray-deposited + homogenization treatment $\left(450^{\circ} \mathrm{C} / 24 \mathrm{~h}+460^{\circ} \mathrm{C} / 2 \mathrm{~h}\right)+$ hot deformation $(420$ ${ }^{\circ} \mathrm{C}$ by 6.25$)+$ solid solution treatment $\left(470{ }^{\circ} \mathrm{C} / 1 \mathrm{~h}\right)+$ age treatment $\left(120^{\circ} \mathrm{C}\right)$ [29]; (III) as-spray-deposited + hot deformation $\left(420^{\circ} \mathrm{C}\right.$ by 6.25$)+$ solid solution treatment $\left(470{ }^{\circ} \mathrm{C} / 1 \mathrm{~h}\right)+$ age treatment $\left(120^{\circ} \mathrm{C}\right)$ [30]; (IV) as-spray-deposited + hot deformation $\left(460^{\circ} \mathrm{C}\right.$ by $\left.60 \%\right)+$ age treatment $\left(120^{\circ} \mathrm{C}\right)$ (this work). Figure 11 shows the hardness variations as a function of the aging time. The hardness increased with the age time, especially at the early state. The peak hardness values were $210 \mathrm{HV}, 208 \mathrm{HV}, 205 \mathrm{HV}$, and $180 \mathrm{HV}$ when the spray deposited samples were treated with path I, path II, path III, and path IV, respectively. For the path IV, the stages of homogenization treatment and solid solution treatment were eliminated, resulting in a lower energy cost, and the hardness is only slightly less than those in other spray-deposited samples. Thus, a shortened processing method of hot deformation $\left(460^{\circ} \mathrm{C}\right.$ by $\left.60 \%\right)+$ age treatment $\left(120{ }^{\circ} \mathrm{C}\right)$ was developed for the as-spray-deposited $\mathrm{Al}-8.31 \mathrm{Zn}-2.07 \mathrm{Mg}-2.46 \mathrm{Cu}-0.12 \mathrm{Zr}$ alloy in this work.

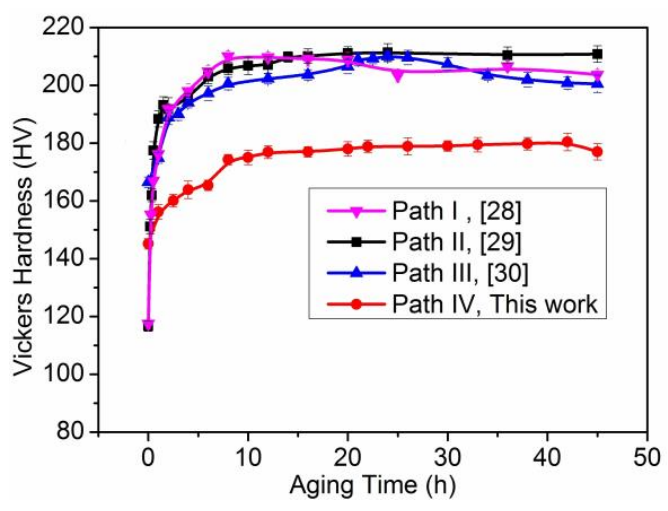

Figure 11. Hardness variations with the aging time with the different paths. 


\subsection{Strengthening Mechanism}

Figure 12 shows the bright-field (BF) TEM images in addition to selected-area diffraction patterns (SADPs) of the spray-deposited alloy treated with the path IV (hot deformation at $460{ }^{\circ} \mathrm{C}$ by $60 \%+$ aging at $120{ }^{\circ} \mathrm{C}$ for $10 \mathrm{~h}$ ). The as-spray deposited alloy were hot compressed by $60 \%$ at $460{ }^{\circ} \mathrm{C}$ and followed by aging at $120^{\circ} \mathrm{C}$ for $10 \mathrm{~h}$; nano-scale precipitates were captured in the BF TEM photographs (Figure 12a). A few diffraction spots from the precipitates were observed from SADPs (Figure 12b). According to the crystal geometry and crystal diffraction, indexing of the SADPs showed that the rod-like precipitates were hexagonal $\eta^{\prime}-\mathrm{MgZn}_{2}$ phase particles with parameters of $a=0.496 \mathrm{~nm}$ and $c=1.402 \mathrm{~nm}$. There is a coherence relationship between $\mathrm{Al}$ and $\eta^{\prime}-\mathrm{MgZn}_{2}:(001)_{\eta^{\prime}} / /(110)_{\mathrm{Al}}$ and $[100]_{\eta^{\prime}} / /[001]_{\mathrm{Al}}$ [31]. Moreover, some nano-scale $\mathrm{Al}_{3} \mathrm{Zr}$ precipitates were detected in the $\mathrm{BF}$ images, as marked by the arrows. Precipitation strengthening is the most effective strengthening mechanism in the studied alloy.

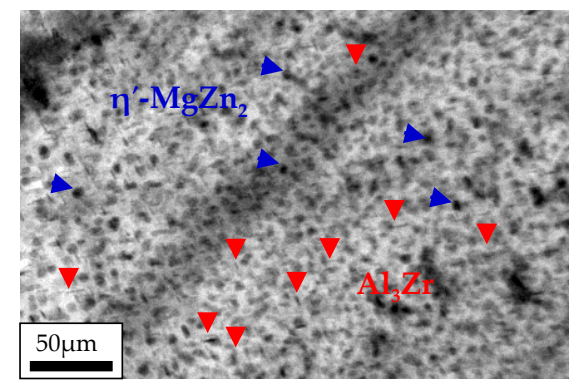

(a)

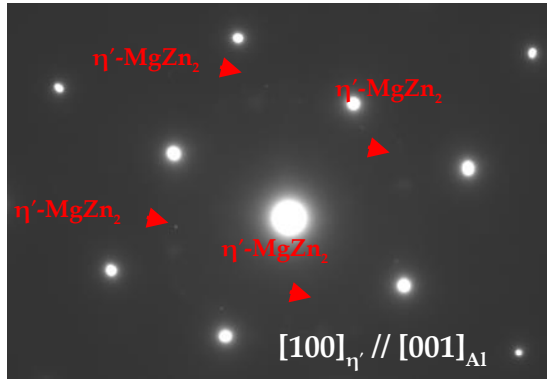

(b)

Figure 12. BF TEM image (a) of the specimen after treat with path $\mathrm{V}$ (hot deformation at $460{ }^{\circ} \mathrm{C}$ by $60 \%$ + aging at $120^{\circ} \mathrm{C}$ for $10 \mathrm{~h}$ ) and the corresponding SADPs (b).

The high strength of the Al-Zn-Mg-Cu-Zr alloy was mainly attributed to precipitation strengthening and grain boundary strengthening.

(I) Precipitation strengthening. An increase in yield stress caused by dislocation bypassing $\eta^{\prime}-\mathrm{MgZn}_{2}$ particles in the Orowan process is given by [32-34]:

$$
\begin{gathered}
\Delta \sigma_{\text {Orowan }}=\frac{0.81 M G b}{2 \pi(1-v)^{1 / 2}} \frac{\ln \left(d_{\mathrm{p}} / b\right)}{\left(\lambda-d_{p}\right)}, \\
\lambda=\frac{1}{2} d_{\mathrm{p}} \sqrt{\frac{3 \pi}{2 f_{\mathrm{v}}}},
\end{gathered}
$$

where $M$ is the Taylor factor, $G$ is the shear modulus, $b$ is the Burgers vector, $v$ is the Poisson's ratio, $\lambda$ is the space between particles, $d_{\mathrm{p}}$ is the average diameter of particles; and $f_{\mathrm{v}}$ is the volume fraction of $\eta^{\prime}-\mathrm{MgZn}_{2}$ particles.

(II) Grain boundary strengthening. As shown in the EBSD images, when the studied alloy was hot-compressed to a reduction of $60 \%$ in thickness. For path IV, samples have some grains with a dimension of $40-60 \mu \mathrm{m}$. These grain boundaries hinder the dislocation motion, leading to a remarkable increase in yield strength [34]. An increase in yield stress due to the grain boundary can be estimated using the Hall-Petch equation [35]:

$$
\Delta \sigma_{\mathrm{H}-\mathrm{P}}=k d^{-\frac{1}{2}}
$$

where $k$ is a constant (3.5-4.5 MPa $\cdot \mathrm{mm}^{-1 / 2}$ for $\mathrm{Al}$ alloys [36]), $d$ is the diameter of grain size. The smaller the grain size, the more numerous the boundaries, and the higher the strength of the studied alloy. 


\section{Conclusions}

In summary, an Al-8.31Zn-2.07Mg-2.46Cu-0.12Zr alloy was synthesized using the spray deposition method. In the as-spray-deposited sample, the $\mathrm{MgZn}_{2}$ particles were detected from inside the grain and grain boundary, while some nanoscale $\mathrm{Al}_{3} \mathrm{Zr}$ particles were inside the grain. Hot compression experiments showed that the true-stress increased with the true-strain. The Arrhenius equation was employed to describe the relationship between peaks of the flow stress and the strain rate. The activation energy $Q$ of the studied alloy was $129.9 \mathrm{~kJ} / \mathrm{mol}$, and the constitutive equation was established: $\dot{\varepsilon}=[\sinh (0.017 \sigma)]^{4.049} \exp [19.14-(129.9 / R T)]$. The appropriate hot deformation temperature was determined to be $460^{\circ} \mathrm{C}$. A short processing baseline has been optimized: as-spray-deposited + hot deformation $\left(460{ }^{\circ} \mathrm{C}\right.$ by $\left.60 \%\right)+$ age treatment $\left(\right.$ at $\left.120{ }^{\circ} \mathrm{C}\right)$, by which considerable properties were approached for the studied alloy. The high strength of the studied alloy was mainly attributed to the grain boundary strengthening from small grains with tens of microns, and the precipitation strengthening from nanoscale $\mathrm{MgZn}_{2}$ and $\mathrm{Al}_{3} \mathrm{Zr}$ precipitates.

Acknowledgments: The authors thank to the financial support by the National Key Technology R and D Program (2014BAC03B08), the National Key Research and Development Program of China (2016YFB0301300), the start-up funding from the Central South University, the Fundamental Research Funds for the Central Universities of Central South University (2014ZZTS018), and the Hunan Provincial Innovation Foundation for Postgraduate (CX2014B048).

Author Contributions: Xiaofei Sheng and Qian Lei conceived and designed the experiments; Xiaofei Sheng performed the experiments; Xiaofei Sheng and Qian Lei analyzed the data; Mingpu Wang and Zhu Xiao contributed materials and discussions; and Xiaofei Sheng and Qian Lei wrote the manuscript.

Conflicts of Interest: The authors declare no conflict of interest.

\section{References}

1. Ferguson, J.B.; Schultz, B.F.; Mantas, J.C.; Shokouhi, H.; Rohatgi, P.K. Effect of Cu, Zn, and Mg concentration on heat treating behavior of squeeze cast Al-(10 to 12)Zn-(3.0 to 3.4)Mg-(0.8 to 1)Cu. Metals 2014, 4, 314-321. [CrossRef]

2. Xu, Y.Q.; Zhan, L.H. Effect of creep aging process on microstructures and properties of the retrogressed Al-Zn-Mg-Cu alloy. Metals 2016, 6, 189. [CrossRef]

3. Zhou, M.; Lin, Y.C.; Deng, J.; Jiang, Y.Q. Hot tensile deformation behaviors and constitutive model of an Al-Zn-Mg-Cu alloy. Mater. Des. 2014, 59, 141-150. [CrossRef]

4. Ma, S.M.; Sun, Y.H.; Wang, H.Y.; Lü, X.S.; Qian, M.; Ma, Y.L.; Zhang, C.; Liu, B.C. Effect of a minor Sr modifier on the microstructures and mechanical properties of $7075 \mathrm{~T} 6 \mathrm{Al}$ alloys. Metals 2017, 7, 13. [CrossRef]

5. Zhao, H.L.; Yao, D.M.; Qiu, F.; Xia, Y.M.; Jiang, Q.C. High strength and good ductility of casting Al-Cu alloy modified by $\operatorname{Pr}_{x} \mathrm{O}_{y}$ and $\mathrm{La}_{x} \mathrm{O}_{y}$. J. Alloys Compd. 2011, 509, 43-46. [CrossRef]

6. Lang, Y.J.; Zhou, G.X.; Hou, L.G.; Zhang, J.S.; Zhuang, L.Z. Significantly enhanced the ductility of the fine-grained Al-Zn-Mg-Cu alloy by strain-induced precipitation. Mater. Des. 2015, 88, 625-631. [CrossRef]

7. Yuan, W.H.; Zhang, J.; Zhang, C.C.; Chen, Z.H. Processing of ultra-high strength SiCp/Al-Zn-Mg-Cu composites. J. Mater. Process. Technol. 2009, 209, 3251-3255. [CrossRef]

8. Krasilnikov, N.A.; Sharafutdiniv, A. High strength and ductility of nanostructured Al-based alloy, prepared by high-pressure technique. Mater. Sci. Eng. A 2007, 463, 74-77. [CrossRef]

9. Marlaud, T.; Deschamps, A.; Bley, F.; Lefebvre, W.; Baroux, B. Influence of alloy composition and heat treatment on precipitate composition in Al-Zn-Mg-Cu alloys. Acta Mater. 2010, 58, 248-260. [CrossRef]

10. Sharma, M.M.; Amateau, M.F.; Eden, T.J. Aging response of Al-Zn-Mg-Cu spray formed alloys and their metal matrix composites. Mater. Sci. Eng. A 2006, 424, 87-96. [CrossRef]

11. Dong, J.; Cui, J.Z.; Yu, F.X.; Zhao, Z.H.; Zhuo, Y.B. A new way to cast high-alloyed Al-Zn-Mg-Cu-Zr for super-high strength and toughness. J. Mater. Process. Technol. 2006, 171, 399-404. [CrossRef]

12. Roy, S.B.Y.; Nataraj, B.R.; Suwas, S.; Kumar, S.; Chattopadhyay, K. Accumulative roll bonding of aluminum alloys 2219/5086 laminates: Microstructural evolution and tensile properties. Mater. Des. 2012, 36, 529-539. [CrossRef]

13. Shaeri, M.H.; Salehi, M.T.; Seyyedein, S.H.; Abutalebi, M.R.; Park, J.K. Microstructure and mechanical properties of Al-7075 alloy processed by equal channel angular pressing combined with aging treatment. Mater. Des. 2014, 57, 250-257. [CrossRef] 
14. Sun, N.; Apelian, D. Friction stir processing of aluminum cast alloys for high performance applications. J. Miner. Metal. Mater. Soc. 2011, 63, 44-50. [CrossRef]

15. Naeem,H.T.; Mohammed, K.S.; Ahmad, K.R. Effect of friction stir processing on the microstructure and hardness of an aluminum-zinc-magnesium-copper alloy with nickel additives. Strength Plast. 2015, 116, 1035-1046. [CrossRef]

16. Sharma, M.M.; Amateau, M.F.; Eden, T.J. Hardening mechanisms of spray formed Al-Zn-Mg-Cu alloys with scandium and other elemental additions. J. Alloys Compd. 2006, 416, 135-142. [CrossRef]

17. Dorward, R.C.; Beerntsen, D.J. Grain structure and quench-rate effects on strength and toughness of AA7050 Al-Zn-Mg-Cu-Zr alloy plate. Metall. Mater. Trans. A 1995, 26, 2481-2484. [CrossRef]

18. Sharma, M.M.; Amateau, M.F.; Eden, T.J. Mesoscopic structure control of spray formed high strength Al-Zn-Mg-Cu alloys. Acta Mater. 2005, 53, 2919-2924. [CrossRef]

19. Jia, Y.D.; Cao, F.Y.; Ning, Z.L.; Guo, S.; Ma, P.; Sun, J.F. Influence of second phases on mechanical properties of spray-deposited Al-Zn-Mg-Cu alloy. Mater. Des. 2012, 40, 536-540. [CrossRef]

20. Liu, S.D.; Zhang, X.M.; Chen, X.M.; You, J.H.; Zhang, X.Y. Effect of Zr content on quench sensitivity of AlZnMgCu alloys. Trans. Nonferr. Met. Soc. China 2007, 17, 787-792. [CrossRef]

21. Cai, Y.H.; Liang, R.G.; Su, Z.P.; Zhang, J.S. Microstructure of spray formed Al-Zn-Mg-Cu alloy with Mn addition. Trans. Nonferr. Met. Soc. China 2011, 21, 9-14. [CrossRef]

22. Li, F.X.; Liu, Y.Z.; Jiang, Y.; Luo, X. Effect of processing parameters on the relative density of spray rolling 7050 aluminum alloy strip. Int. J. Adv. Manuf. Technol. 2013, 67, 2771-2778. [CrossRef]

23. Yu, H.C.; Wang, M.P.; Sheng, X.F.; Li, Z.; Chen, L.B.; Lei, Q.; Chen, C.; Jia, Y.L.; Xiao, Z.; Chen, W.; et al. Microstructure and tensile properties of large-size 7055 aluminum billets fabricated by spray forming rapid solidification technology. J. Alloys Compd. 2013, 578, 208-214. [CrossRef]

24. Sellars, C.M.; McTegart, W.J. On the mechanism of hot deformation. Acta Metall. 1966, 14, 1136-1138. [CrossRef]

25. Medina, S.F.; Hernandez, C.A. General expression of the Zener-Hollomon parameter as a function of the chemical composition of low alloy and microalloyed steels. Acta Mater. 1996, 44, 137-148. [CrossRef]

26. Kolb, G.K.H.; Scheiber, S.; Antrekowitsch, H.; Uggowitzer, P.J.U.; Pöschmann, D.; Pogatscher, S. Differential scanning calorimetry and thermodynamic predictions-A comparative study of Al-Zn-Mg-Cu alloys. Metals 2016, 6, 180. [CrossRef]

27. Wu, H.; Wen, S.P.; Huang, H.; Gao, K.Y.; Wu, L.X.; Wang, W.; Nie, Z.R. Hot deformation behavior and processing map of a new type Al-Zn-Mg-Er-Zr alloy. J. Alloys Compd. 2016, 685, 869-880. [CrossRef]

28. Wang, Z.A.; Wang, M.P.; Yang, W.C.; Zhang, Q. Ageing precipitation and hardening behavior of 1973 high strength and high toughness aluminum alloy. Chin. J. Nonferr. Met. 2011, 21, 522-528.

29. Yu, H.C. Microstructure and Mechanical Properties of Spray-Deposition 7055 High Strength Aluminum Alloys. Ph.D. Thesis, Central South University, Changsha, China, May 2015. (In Chinese)

30. Liu, B.; Wang, M.P.; Lei, Q.; Daun, Y.L.; Liu, L.X.; Yu, H.C. Microstructure and properties of Al-Zn-Mg-Cu-Zr alloy prepared by spray deposition method. Chin. J. Nonferr. Met. 2015, 25, 1773-1780.

31. Totten, G.E.; MacKenzie, D.S. Handbook of Aluminum; Marcel Dekker, Inc.: New York, NY, USA, 2003; Volume 1, pp. 287-288, ISBN:0824704940.

32. Mabuchi, M.; Higashi, K. Strengthening mechanism of Mg-Si alloys. Acta Mater. 1996, 44, 4611-4618. [CrossRef]

33. Lee, J.S.; Jung, J.Y.; Lee, E.K.; Park, W.J.; Ahn, S.; Nack, J.K. Microstructure and properties of titanium boride dispersed $\mathrm{Cu}$ alloys fabricated by spray forming. Mater. Sci. Eng. A 2000, 277, 274-283. [CrossRef]

34. Zhou, Y.J.; Song, K.X.; Xing, J.D.; Zhang, Y.M. Precipitation behavior and properties of aged Cu-0.23Be-0.84Co alloy. J. Alloys Compd. 2016, 658, 920-930. [CrossRef]

35. Yang, G.; Li, Z.; Yuan, Y.; Qian, L. Microstructure, mechanical properties and electrical conductivity of $\mathrm{Cu}-0.3 \mathrm{Mg}-0.05 \mathrm{Ce}$ alloy processed by equal channel angular pressing and subsequent annealing. J. Alloys Compd. 2015, 640, 347-354. [CrossRef]

36. Zheng, Z.Q. Fundamentals of Materials Science; Central South University Press: Changsha, China, 2005; pp. 302-306. ISBN 978-7-5487-0948-0. (In Chinese)

(C) 2017 by the authors. Licensee MDPI, Basel, Switzerland. This article is an open access article distributed under the terms and conditions of the Creative Commons Attribution (CC BY) license (http:/ / creativecommons.org/licenses/by/4.0/). 